\title{
The one-stop coronary cholesterol clinic: a multidisciplinary approach to implementing evidence-based treatment
}

\author{
PD Giles, S Ramachandran, AJ Whitaker, AW Phillips, SJ Fell, A Mitchell, TD Coleman
}

\begin{abstract}
Summary
We describe a 'one-stop' cholesterol clinic implementing a regime based on the Scandinavian Simvastatin Survival Study (4S) in patients with established coronary heart disease in a district general hospital. The clinic has been established in collaboration with the cardiac rehabilitation centre. It was commissioned as an audit project by the purchasing authority, Walsall Health, a need having been shown in a previous audit. In the new clinic, audit is inbuilt, rather than being carried out as a separate retrospective exercise, and undertaken prospectively for all patients. Central to this is a database, used for routine correspondence and administration, as well as monitoring outcome. This application of information technology has improved clinical practice. Attendance at the clinic has been excellent. Half the consultations have resulted in therapeutic interventions, many of which may otherwise have been missed. Over $50 \%$ of patients were eligible for lipid-lowering medication under the protocol. Cholesterol targets based on $4 S$ were achieved but with much lower drug doses, which may have major cost implications. Cholesterol levels measured within 24 hours of admission for myocardial infarction were poor predictors of results obtained after convalescence. After the clinic visit, most patients were taking aspirin plus one or two other secondary prevention treatments. Guidelines have been issued to primary care. Future plans for audit links with general practitioners, integration of the metabolic and cardiological assessment of survivors of myocardial infarction, and for long-term monitoring of clinical events in treated patients are discussed.
\end{abstract}

Department of Biochemistry, Manor Hospital, Walsall, West Midlands, WS2 9PS, UK PD Giles $S$ Ramachandran AJ Whitaker AW Phillips SJ Fell A Mitchell TD Coleman

Implementation, rather than discovery, may limit improvement in healthcare. ${ }^{1}$ Recently, an approach to increase the use of drugs of proven value for secondary prevention after myocardial infarction has been reported but lipidlowering medication was not considered. ${ }^{2}$ The Scandinavian Simvastatin Survival Study $(4 S)^{3,4}$ provided compelling evidence that outcome in patients with coronary heart disease may be substantially improved by cholesterol reduction with drugs. The value of cholesterol-lowering medication in coronary heart disease is increasingly accepted ${ }^{5}$ and strategies are being proposed for choosing combinations of secondary prevention measures (including cholesterol reduction) for individual patients. 6,7

Reduction in coronary deaths is a priority in Walsall. The district includes areas of urban deprivation and about $8 \%$ of the population of 263000 are of Asian extraction. Most acute services are provided by the Manor Hospital, a nonteaching National Health Service (NHS) trust. Following the publication of $4 \mathrm{~S}$ in November 1994, copies of cholesterol results obtained within 24 hours of patients' admission to the Manor Hospital coronary care unit were sent directly to general practitioners. Each report was accompanied by a letter summarising $4 \mathrm{~S}$ and asking general practitioners to check their patients' lipids two to three months later, when many uncomplicated myocardial infarction cases would already have been discharged from hospital follow-up. When compliance with this recommendation was assessed during early 1995, it was found that the retest rate was disappointingly low. If patients were not being retested, there seemed little chance that their lipids would be treated unless a new approach were taken.

\section{Methods}

Three-quarters of Walsall myocardial infarction survivors embark on a 12-week cardiac rehabilitation course, 'Heartcare'. As a new initiative it was decided to offer lipid testing to Heartcare patients towards the end of their course and to discuss the results with each patient in a 'one-stop' Coronary Cholesterol Clinic. Where appropriate, treatment would be initiated using a $4 \mathrm{~S}$-based protocol (see below). Subsequently the opportunity to attend the clinic has been extended to other coronary heart disease patients.

Steps have been taken to gain the support of

general practitioners. The protocol was submitted to the Local Medical Committee and discussed with Walsall Medical Audit Advisory Group. Follow-up guidelines have been distributed to all Walsall general practitioners as a poster. An explanatory article has been published in Walsall Health's general practitioner 
newsletter and a series of talks for general practitioners and practice nurses has been given by the consultant chemical pathologist. The project has been endorsed by the two cardiologists at the Manor Hospital.

At the one-stop clinic the threshold for starting lipid-lowering medication (after at least three months diet) is $5.5 \mathrm{mmol} / \mathrm{l}$, with a target of $5.2 \mathrm{mmol} / 1$ or less (taken from $4 \mathrm{~S}$ ). The cardiac rehabilitation nurse specialist sees patients with cholesterol up to $5.5 \mathrm{mmol} / \mathrm{l}$ and patients over the age of 70 . Patients up to the age of 70 with cholesterol levels above 5.5 $\mathrm{mmol} / \mathrm{l}$ are seen by the consultant or registrar in chemical pathology, who initiate lipid-lowering medication provided that diet is satisfactory and that there are no contraindications to treatment. All patients with clinic cholesterol levels in excess of $5 \mathrm{mmol} / \mathrm{l}$ are retested after about two months (irrespective of whether they are taking lipid-lowering drugs), unless there is a contraindication to lipid treatment. Further tests are arranged if the first post-clinic checks are unsatisfactory. Second outpatient appointments are not given routinely but patients are requested to contact the clinic if they have difficulties with their treatment. General practitioners are asked to undertake long-term follow-up, according to the local guidelines.

Central to the scheme is a database. A proforma is completed by the doctor/nurse for each patient, documenting major risk factors for coronary heart disease, the lipid record and regular drug use prior to the clinic (including agents being taken for secondary prevention). The information is entered into the database, from which a structured letter is generated, including treatment recommendations and, where appropriate, a date for retesting the lipids. Copies are sent to both general practitioner and patient. On a rolling basis, the database generates lists of patients due for follow-up testing. Reminders are sent to patients who fail to attend for retests. As patients are retested, their cumulative lipid record is updated, and new recommendations for lipid treatment and retesting are sent to both general practitioner and patient.

The Walsall protocol differs from $4 \mathrm{~S}$ in certain respects. First, drugs other than simvastatin are sometimes used. Fibrates are occasionally recommended for patients with triglyceride in excess of $2.5 \mathrm{mmol} / 1$ (such patients were excluded from 4S). It is accepted that the benefits/safety of different types of lipid-lowering drugs may not be equivalent. ${ }^{8}$ Pravastatin has been shown to reduce coronary risk without adverse effect in a primary prevention trial in Scotland. ${ }^{9}$ Trials with other lipid-lowering drugs are in progress. ${ }^{10,11}$ In practice, however, simvastatin is much the most commonly used lipid-lowering drug in the one-stop clinic (95\%). Second, patients on angiotensin-converting enzyme inhibitors and or diuretics because of impaired cardiac function, or with arrhythmias were excluded from $4 S$, whereas, in the one-stop clinic, patients graded as 3 or 4 on the New York Heart Association classification of heart failure ${ }^{12}$ are considered unsuitable for lipid treatment.
Third, patients in their early seventies are occasionally seen in the one-stop clinic. $\mathrm{Li}$ pid-lowering drugs are recommended in a few of these cases where general health (apart from coronary disease) is good; otherwise dietary advice is reinforced (subgroup analysis of $4 \mathrm{~S}$ showed benefit in patients aged over 60 years but the trial did not recruit patients over 70 ).

Lipid analyses were performed on a Beckman CX5 analyser, using the manufacturer's reagents. Paired data were compared by the Wilcoxon matched-pairs signed ranks test. Microsoft Works for Windows (version 3) was used to form the database.

\section{Results}

\section{ACTIVITY AND TREATMENT DECISIONS}

Between 15 May 1995 and 31 January 1996 19 clinics were held, in which 267 patients were seen. In addition, one patient declined to attend the clinic in advance and two other patients failed to attend their appointments without explanation. The basic characteristics of the 267 patients are shown in the table.

Lipid-lowering medication was started in 107 patients $(40 \%)$ and adjusted (by dose or type) in $21(8 \%)$. Five patients declined treatment. In addition, lipid-lowering medication was stopped in one patient and continued without alteration in $22(8 \%)$. In the remaining 111 patients (42\%) dietary advice was reinforced.

The number of patients taking lipid therapy before their visit to the one-stop clinic was 44 $(16.5 \%)$, whereas the number after the visit was 150 (56\%). In 129 of the 267 consultations (48\%) a change in lipid therapy was implemented. After the one-stop review, most patients were taking aspirin plus one or two other secondary prevention measures (table).

\section{POST-CLINIC FOLLOW-UP TESTS: RESPONSE TO} TREATMENT

Of the 172 patients due for post-clinic retesting by 31 January 1996, 161(94\%) had attended. These cases comprised a mixture of patients in whom lipid-lowering medication was either started, or changed in dose or type, at the onestop clinic, and other patients whose lipid treatment was not altered at the clinic but who had cholesterol levels over $5 \mathrm{mmol} / \mathrm{l}$.

Of these 161 patients, 95 (59\%) had retest cholesterol levels of $5.2 \mathrm{mmol} / 1$ or less, as compared with $20(12.4 \%)$ of them at the onestop clinic. The mean reduction in cholesterol was $1.01 \mathrm{mmol} / \mathrm{l}$ (CI 0.85-1.17), $\mathrm{p}<0.0001$

Seventy-five of the 161 retested patients had been started on $10 \mathrm{mg}$ simvastatin at the clinic (no lipid-lowering drugs having been given previously). The mean cholesterol reduction was $1.71 \mathrm{mmol} / \mathrm{l}$ (CI $1.55-1.87$ ) (26\%), $\mathrm{p}<0.0001$. The cholesterol was reduced to $5.2 \mathrm{mmol} / 1$ or less in $62 / 75(83 \%)$ of these patients,all of whom had pre-treatment cholesterol levels of $5.5 \mathrm{mmol} / \mathrm{l}$ or more. A decrease in cholesterol was recorded in all except two patients in this group, both of whom reported that they had stopped treatment because of apparent side-effects. 
Table Characteristics of patients attending one-stop coronary cholesterol clinic $(n=267)$

\begin{tabular}{|c|c|}
\hline $\begin{array}{l}\text { Age in years }(\mathrm{SD}) \\
\text { Body mass index }\left(\mathrm{kg} / \mathrm{m}^{2}\right)(\mathrm{SD}) \\
\text { Male/female }\end{array}$ & $\begin{array}{l}60.7(10.2) \\
26.8(4.1) \\
205 / 62(77 \% / 23 \%)\end{array}$ \\
\hline $\begin{array}{l}\text { Pre-clinic events } \\
\text { Myocardial infarction } \\
\text { Coronary artery bypass grafting } \\
\text { Angioplasty } \\
\text { Cerebovascular disease }\end{array}$ & $\begin{array}{l}240(90 \%) \\
35(13 \%) \\
5(2 \%) \\
3(1 \%)\end{array}$ \\
\hline $\begin{array}{l}\text { Current symptoms } \\
\text { Angina } \\
\text { Peripheral vascular disease } \\
\text { Heart failure (NYHA) Grade 1 } \\
\text { Grade 2 } \\
\text { Grade 3 }\end{array}$ & $\begin{array}{l}124(46 \%) \\
7(3 \%) \\
188(70 \%) \\
67(25 \%) \\
12(5 \%)\end{array}$ \\
\hline $\begin{array}{l}\text { Smoking habits } \\
\text { Current smokers } \\
\text { Recent ex-smokers } \\
\text { Long term ex-smokers } \\
\text { Never smoked } \\
\text { Pipe/cigar smokers }\end{array}$ & $\begin{array}{l}21(8 \%) \\
40(15 \%) \\
128(48 \%) \\
72(27 \%) \\
6(2 \%)\end{array}$ \\
\hline $\begin{array}{l}\text { Significant family history } \\
\text { First degree } \\
\text { Second degree }\end{array}$ & $\begin{array}{l}94(35 \%) \\
30(11 \%)\end{array}$ \\
\hline $\begin{array}{l}\text { Other risk factors } \\
\text { Hypertension } \\
\text { Diabetes }\end{array}$ & $\begin{array}{l}59(22 \%) \\
20(7 \%)\end{array}$ \\
\hline $\begin{array}{l}\text { Medication } \\
\text { Aspirin } \\
\text { Beta blockers } \\
\text { ACE inhibitors (including } 30 \\
\text { treated for hypertension) }\end{array}$ & $\begin{array}{l}245(92 \%) \\
103(39 \%) \\
57(21 \%)\end{array}$ \\
\hline $\begin{array}{l}\text { Lipids } \\
\text { Cholesterol } \\
\text { on admission }(n=115) \\
\text { after recovery }(n=267) \\
\text { follow-up }(n=161)\end{array}$ & $\begin{array}{l}\text { mean (mmol/l) (SD) } \\
6.08(1.08) \\
5.97(1.00) \\
5.22(0.88)\end{array}$ \\
\hline $\begin{array}{l}\text { Triglycerdes } \\
\text { after recovery }(n=261) \\
\text { follow-up }(n=156)\end{array}$ & $\begin{array}{l}1.93(1.04) \\
1.70(0.90)\end{array}$ \\
\hline $\begin{array}{l}\text { HDL cholesterol } \\
\text { after recovery }(n=257) \\
\text { follow-up }(n=154)\end{array}$ & $\begin{array}{l}0.99 \\
1.05(0.27) \\
(0.26)\end{array}$ \\
\hline
\end{tabular}

Attendance at the one-stop clinic was very satisfactory and resulted in a high proportion of therapeutic decisions, many of which may not otherwise have been implemented

Evidence-based cholesterol targets were achieved in patients selected for lipid-lowering medication at the one-stop clinic but patients maintained on diet alone showed no overall change on follow-up

For comparison, $72 \%$ of patients in the active-treatment arm of $4 \mathrm{~S}$ (taking $20-40 \mathrm{mg}$ simvastatin) were within the target of 5.2 $\mathrm{mmol} / \mathrm{l}$ or less at one year. The average cholesterol reduction was $28 \%$ at six weeks, when all patients were still on $20 \mathrm{mg}$, and $25 \%$
Even samples obtained during the first 24 hours of an admission for myocardial infarction cannot be used to exclude a lipid-problem; all patients should be retested after convalescence, unless there is a contraindication to lipid therapy

$(1.8 \mathrm{mmol} / \mathrm{l})$ later in the trial. The slight attenuation in average cholesterol reduction with time in $4 S$ and other 'statin' trials analysed by intention to treat ${ }^{9,13}$ is thought to be due to dilution by patients who stopped treatment but continued to provide blood samples. Treatment effect with simvastatin is not thought to diminish in patients who continue to comply with therapy.

By contrast with the drug-treated group, the 33 patients who continued without lipid-lowering medication after attending the one-stop clinic and who had been retested by 31 January 1996 showed no significant change overall (5.7 before vs $5.8 \mathrm{mmol} / 1$ after). Amongst this group were elderly patients with cholesterol levels over $5.5 \mathrm{mmol} / \mathrm{l}$ in whom dietary advice had been reinforced, and some younger patients who had declined lipid-lowering medication. In one exceptional patient the cholesterol fell from 8.2 (measured on admission to the coronary care unit) to $6.3 \mathrm{mmol} / 1$ shortly before his one-stop clinic review. Although simvastatin was recommended he refused it and with further dietary effort the cholesterol fell to $5 \mathrm{mmol} / \mathrm{l}$ two months later.

CHOLESTEROL MEASUREMENTS ON THE CORONARY CARE UNIT

It has been suggested that samples obtained within 24 hours of myocardial infarction give a reliable guide to a patient's pre-morbid lipid status, although subsequently total serum cholesterol falls as part of the response to tissue injury before rising again as convalescence is completed. ${ }^{14}$ In the present study the average total cholesterol in 93 samples obtained within 24 hours of admission to the coronary care unit from patients who were not started on lipid-lowering drugs at that stage $(5.9 \mathrm{mmol} / \mathrm{l})$ did not differ significantly from the mean level in the same patients three or more months later $(5.8 \mathrm{mmol} / \mathrm{l})$. However, this conceals a wide variation between individuals (figure), which is due to the interaction of diverse factors, including acute phase effects, diet, drugs, sampling conditions and analytical imprecision.

\section{Discussion}

The average cholesterol decrease in one-stop clinic patients accepting simvastatin approached that seen in the treatment arm of 4S. The data from $4 S$ indicated that a cholesterol reduction of this size, if sustained for five or six years, should prevent four of the nine expected deaths from coronary heart disease per 100 patients treated. Additionally, substantial amelioration of recurrent non-fatal myocardial infarction and need for revascularisation procedures would also be anticipated; 


\section{Learning points}

- coronary heart disease is an area ripe for audit, several treatments (including cholesterol reduction) having proven benefit

- routine patient management and prospective accumulation of audit data can be integrated through information technology. This is best organised at the outset if a new service is being initiated

- when treatment is started in hospital but requires long-term continuation by general practitioners, appropriate audit links between primary and secondary care must be established

- treatment regimes used in clinical trials may require modification when applied to individual patients in routine clinical practice

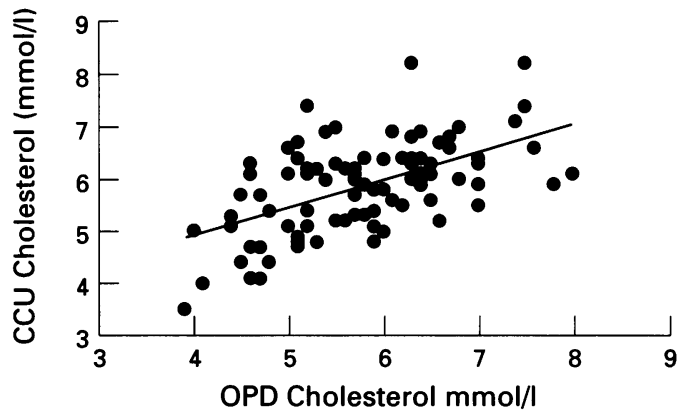

Figure The relationship between serum cholesterol levels measured on samples obtained within 24 hours of admission to the coronary care unit (CCU) and those recorded after recovery (OPD) in patients not given lipid-lowering medication $(n=93, \mathrm{y}=0.528 \mathrm{x}+2.817$, $\mathrm{r}={ }^{2} 0.303, \mathrm{p}=0.27$ )

in $4 \mathrm{~S}$, treatment reduced these by about a third.

Although most patients seen in the one-stop clinic had undergone several lipid tests, the pre-clinic profile was used as the main basis for therapeutic decisions for two reasons. First, $4 \mathrm{~S}$ demonstrated that relative risk reduction in treated patients is independent of the baseline cholesterol. ${ }^{4}$ Therefore, if after three months compliance with diet a patient is seen as a candidate for treatment, in the typical case there is little advantage in delaying the decision in order to define the baseline more precisely and much to be gained by seeking the greatest cholesterol reduction possible. Second, the likelihood of patients defaulting from followup may increase if multiple tests are undertaken without action.

Although high-density lipoprotein (HDL) cholesterol and triglyceride concentrations were assayed in nearly all one-stop patients, in practice most decisions were made on the total cholesterol. This may seem crude but was the strategy adopted in $4 \mathrm{~S}$. The value of HDL measurements is in refining coronary heart disease risk assessment but in a group of patients with established coronary disease, risk is necessarily high, so HDL levels may be less helpful in this context than in estimating future risk in an individual without current coronary heart disease. However, when further information becomes available from on-going trials of lipid treatment in coronary heart disease, ${ }^{10,11}$ the Walsall protocol may require modification to take into account HDL and calculated lowdensity lipoprotein (LDL) concentrations.

The long-term financial consequences of this treatment are important. Lipid-lowering medication in myocardial infarction survivors appears cost-effective when compared with other interventions, such as thrombolysis, coronary artery by-pass grafting and breast cancer screening. ${ }^{15,16}$ However, it must be recognised that the immediate costs will fall on primary care, while the major savings will be in hospital expenditure and will only accrue later.

Although typical drug doses in the one-stop clinic were substantially lower than those used in $4 \mathrm{~S}$, a similar proportion of simvastatintreated patients achieved the target cholesterol of $5.2 \mathrm{mmol} / \mathrm{l}$ or less. Even though some of the Walsall patients may have benefited from a further increase in simvastatin, experience in the one-stop clinic is probably a better guide to the potential costs of implementing lipid-lowering therapy in myocardial infarction survivors in a routine clinical setting than is the dosage regime used in $4 \mathrm{~S}$ and cost-effectiveness may be considerably better than has previously been supposed.

Following the success of this one-stop approach, discussions are taking place with the cardiologists at the Manor Hospital about a multidisciplinary one-stop post-myocardial infarction clinic to include all aspects of assessment, not just the metabolic.

The success of lipid-lowering strategies depends on long-term compliance: clinical benefits are not seen until after 12-18 months of therapy but then become progressively greater as treatment is prolonged. ${ }^{4,9}$ Although the one-stop clinic has been successful in initiating therapy in targeted patients, treatment must be continued indefinitely in primary care. A variety of factors may mitigate the ideal. It is vital that there is on-going monitoring of patients who have been commenced on medication. Audit of these and similar patients must be given a high priority in primary care. The database developed for the one-stop clinic has the capacity to be adapted as a long-term recall mechanism to assist general practitioners with appropriate interval testing and, in collaboration with Walsall Medical Audit Advisory Group, it is hoped to begin piloting this extension to the original scheme over the next few months.

Ideally, actual clinical events, as well as the metabolic effects of treatment, should be followed in patients. Few districts have high quality record linkage systems, although with the advent of a unique NHS patient number this may become easier. The information department at Walsall Health is hoping to monitor successive cohorts of patients for coronary heart disease events (including need for angiography, coronary artery bypass grafting/angioplasty, repeat myocardial infarction and death) over the coming years. 
This project was funded by Walsall Health. Thanks are due to Mr DC Crothers (Biochemistry Department, Manor Hospital) for help with data analysis.

This audit was carried out at the Manor Hospital,

1 Smith R. The scientific basis of health services. $B M F$ 1995; 311: 961-2.

2 Smith J, Channer KS. Increasing prescription of drugs for secondary prevention after myocardial infarction. $B M \mathcal{F}$ 1995; 311: 917-918.

3 Scandinavian Simvastatin Survival Group. Randomised trial of cholesterol lowering in $\mathbf{4 4 4 4}$ patients with coronary heart disease: the Scandinavian Simvastatin Survival Study(4S). Lancet 1994; 344: 1383-9.

4 Scandinavian Simvastatin Survival Group. Baseline serum cholesterol and treatment effect in the Scandinavian cholesterol and treatment effect in the Scandinavian Simvastatin Survival Study(4S). Lancet 1995; 345: 1274-5. Oliver M, Poole-Wilson P, Shepherd J, Tikkanen MJ. 6 Lower patients' cholesterol now. BMJ 1995; 310: $1280-1$. 6 Channer KS. Choosing drugs for secondary prevention after myocardial infarction: a pragmatic approach. Postgrad Med
1995; 71: 321-2.

after infarction. Prescribers' $\mathcal{F}$ 1995; 35: 149-58.

8 Gould AL, Rossouw JE, Santanello NC, Heyse JF, Furberg $\mathrm{CD}$. Cholesterol reduction yields clinical benefit. Circulation 1995; 91: 2274-82.

9 Shepherd J, Cobbe SM, Ford I, et al. Prevention of coronary heart disease with pravastatin in men with hyper-cholesterolaemia. N Engl f Med 1995; 333: 1301-7.
Walsall (Walsall Hospitals NHS Trust), in collaboration with Walsall Heartcare (cardiac rehabilitation centre) having been commissioned by Walsall Health.

10 Goldbourt U, Behar S, Reicher-Reiss H, et al. Rationale and design of a secondary prevention trial of increasing serum high-density lipoprotein cholesterol and reducing triglycerides in patients with clinically manifest atherosclerotic heart disease (the bezafibrate infarction prevention trial). $A m$ Cardiol 1993; 71: 909-15.

11 McGovern ME Clinical trials with pravastatin: reduction in morbidity and mortality (review) Br $\mathcal{F}$ Cardiol 1995; (suppl 2): S13-4

12 Criteria Committee, New York Heart Association, Inc Diseases of the heart and blood vessels. Nomenclature and criteria for diagnosis, 6th edn. Boston: Little, Brown and Co, 1964; for diagno

13 Keech A, Collins R, MacMahon, et al. Three-year follow-up of the Oxford cholesterol study: assessment of the efficacy and safety of simvastatin in preparation for a large mortality study. Eur Heart f 1994; 15: 255-69.

14 Ryder REJ, Hayes TM, Mulligan IP, et al. How soon afte myocardial infarction should plasma lipid values be assessed? BMF 1984; 289: 1651-3.

15 Jonsson B, Johannesson $M$, Kjekshus $J$, et al. Cost effectiveness of cholesterol lowering. Eur Heart f 1996; 17: 1001-7.

16 Davey Smith G, Pekkanen J. Scandinavian simvastatin survival study (letter). Lancet 1994; 344: 1766.

\section{Medical Anniversary}

\section{GEORGE MINOT, 2 DECEMBER 1885}

George Minot (1885 - 1950) was born in Boston, Massachusetts, son of a local doctor. He became MD (Harvard) (1912) and spent his working life as a haematologist. He showed the value of liver (and later vitamin B12) in the treatment of pernicious anaemia, for which he shared the Nobel prize with William Murphy and Dr Whipple in 1934. He died on 25 February 1950. - DG fames 